\title{
O Regime Geral da Previdência do Brasil: uma abordagem crítica*
}

\author{
The General Regime of Social Security in Brazil: A Critical Approach
}

Daniel Nogueira Silva e Henrique Morrone**

\begin{abstract}
Resumo: A previdência social tem um papel importante na garantia de condições mínimas de sobrevivência para parte significativa da população brasileira. Nas últimas décadas, os sistemas previdenciários ao redor do mundo, incluindo o do Brasil, passaram a enfrentar maiores dificuldades de assegurar seu equilíbrio financeiro e atuarial, colocando dúvidas sobre sua sustentabilidade. Nesse sentido, o presente artigo busca ampliar a compreensão dos desafios que se colocam para a previdência social brasileira, empregando instrumentos teóricos e metodológicos para além daqueles que são utilizados pelo mainstream econômico. Para alcançar esse objetivo, este artigo analisa o Regime Geral da Previdência no Brasil, focando em alguns indicadores previdenciários que incorporam variáveis ligadas ao mercado de trabalho e a estrutura econômica, como a produtividade. Com base nos indicadores utilizados, os resultados apontam que apesar do sistema previdenciário brasileiro enfrentar dificuldades, tanto o diagnóstico quanto os instrumentos para reverter o atual quadro são limitados. Lidar com tais questões passa por políticas econômicas voltadas para a redução da informalidade, ampliação da produtividade e por um melhor uso dos recursos advindos do Estado para financiar o sistema.
\end{abstract}

Palavras-chave: Regime Geral da Previdência; Dinâmica Previdenciária; Razão de Dependência; Custo Macroeconômico

Abstract: The Social security has an important role in guaranteeing minimum survival conditions for a significant part of the Brazilian population. In the last decades, social security systems around the world, including Brazil's, have faced greater difficulties in ensuring their financial and actuarial balance, raising doubts about their sustainability. In this sense, this article seeks to broaden the understanding of the challenges facing the Brazilian social security, by using theoretical and methodological instruments in addition to those used by the economic mainstream. To achieve this objective, this article analyzes the General Social Security Regime in Brazil, focusing on some social security indicators that incorporate variables related to the labor market and the economic structure, such as productivity. Based on the indicators used, the results show that although the Brazilian social security system faces difficulties, both the diagnosis and the instruments to revert

\footnotetext{
* Submissão: 17/03/2020 | Aprovação: 01/08/2020 |DOI: 10.5380/re.v42i78.70160

** Respectivamente: (1) Professor da Faculdade de Ciências Econômicas da Universidade Federal do Sul e Sudeste do Pará (Unifesspa) | E-mail: daniel.nogueira@ unifesspa.edu.br | ORCID: 0000-0002-8379-4672 | (2) Professor da Faculdade de Ciências Econômica da Universidade Federal do Rio Grande do Sul (UFRGS) | E-mail: hmorrone@ hotmail.com | ORCID: 0000-0001-9579-8489
} 
the current situation are limited. Dealing with such issues involves economic policies aimed at reducing informality, increasing productivity and a better use of resources coming from the State to finance the system.

Keywords: General Social Security Regime; Social Security Dynamics; Dependency Ratio; Macroeconomic Cost

JEL: H50; H55; H60 


\section{Introdução}

A previdência social tem um papel importante na garantia de condições mínimas de sobrevivência para parte significativa da população brasileira. Combater a pobreza na velhice (Camarano et al., 2013; Reis et al., 2015), reduzir as diferenças de ganhos entre homens e mulheres (Marri et al., 2010) e entre as regiões (Caetano; Monasterio, 2014; Reis; Turra, 2011), dinamizar a economia dos pequenos e médios municípios (França, 2011), são alguns dos efeitos positivos gerados pela Previdência no Brasil. Contudo, na maior parte das avaliações sobre a previdência, esses ganhos são desconsiderados e o foco da análise se restringe ao custo fiscal.

Ao analisar a dinâmica da previdência no Brasil, vários trabalhos argumentam que, na elaboração da Constituição Federal (CF) de 1988, faltou uma equiparação das receitas como contrapartida para o aumento dos gastos previdenciários trazidos pela nova Constituição (Giambiagi et al., 2004; Giambiagi; Além, 2011). Segundo os autores que defendem essa posição, os constituintes não definiram quais seriam as fontes de recursos que permitiriam o financiamento desses gastos. A principal consequência foi que já em 1995, poucos anos depois de ter sido estabelecida a nova constituição, houve o início das discussões sobre a reforma da previdência, com o risco de que, caso ela não fosse feita, o sistema previdenciário não teria condições de garantir o seu equilíbrio financeiro e atuarial (Bacha, 2004; Marques et al., 2003; Silva; Schwarzer, 2002). Assim, a realização de um conjunto de reformas, incluindo a última que foi realizada a partir da Emenda Constitucional 103 de 2019, tornavase imprescindível para garantir a sustentabilidade do sistema previdenciário.

De um modo geral, as reformas da previdência podem ser divididas em dois grupos. No primeiro estão as chamadas reformas paramétricas. Nela, busca-se modificar algumas normas do sistema, como a idade da aposentadoria, o tamanho dos benefícios, o percentual de contribuição, entre outros parâmetros. Um dos seus principais objetivos é tornar as regras previdenciárias mais compatíveis com a realidade demográfica sem, contudo, alterar estruturalmente o sistema. No Brasil, todas as reformas previdenciárias realizadas a partir da Constituição Federal podem ser colocadas nesse primeiro grupo.

No segundo estão as reformas estruturais. Nesse caso é feita uma mudança do modelo previdenciário, que deixa de ser de repartição simples e passa a ser um 
sistema de capitalização privada, ou vice-versa. No regime de repartição simples, como o que predomina no Brasil, o sistema de previdência está estruturado de modo que a geração atual de trabalhadores seja responsável por financiar os gastos previdenciários dos aposentados e pensionistas. Já no sistema capitalizado, cada trabalhador contribui ao longo da sua vida, gerando uma poupança privada que será paga no momento da sua aposentadoria ou caso ele fique incapacitado.

Tratando do caso brasileiro, sem entrar no mérito dos impactos econômicos e sociais que diferentes reformas podem gerar, o ponto central do argumento desenvolvido neste artigo é que nem sempre essas reformas partem de um diagnóstico correto do problema enfrentado pela previdência, como foi o caso da reforma previdenciária proposta a partir da Proposta de Emenda Constitucional (PEC) 06/2019. Isso ocorre por diversos motivos, sendo que dois deles são analisados mais detalhadamente nesse trabalho. O primeiro está relacionado com o dimensionamento do resultado previdenciário (diferença entre as receitas e despesas). Para avaliar e propor reformas, é fundamental ter uma visão precisa da dimensão dos problemas enfrentados, para que as reformas propostas atinjam as causas fundamentais que geram os desequilíbrios fiscais (Gentil, 2006). O segundo motivo é que existem diversos fatores que atuam indiretamente sobre o resultado previdenciário e não são considerados nos indicadores convencionais de análise da previdência, o que limita a avaliação da sustentabilidade do sistema (Puty et al., 2017).

Recentemente, diversos trabalhos têm buscado analisar a previdência social a partir de uma perspectiva não convencional, explorando variáveis que muitas vezes são desconsideradas no debate da previdência. Sobre o dimensionamento do gasto previdenciário, um trabalho a destacar é o de Gentil (2006), que analisa as despesas e receitas do Regime Geral da Previdência no Brasil no período de 1990 a 2005. Com base em sua metodologia, a autora recalcula os valores das receitas e despesas, chegando a conclusões sobre o resultado da previdência que são diferentes das divulgadas pelos órgãos oficiais. Gentil et al. (2017) vai citar as Desonerações Fiscais e a Desvinculação das Receitas da União como dois fatores que influenciam negativamente a capacidade de arrecadação da seguridade social, e, consequentemente, a previdência, mas que não são levados em consideração quando se discute as reformas previdenciárias. 
Como apontado em Puty et al. (2017), desconsiderar variáveis econômicas e sociais leva a um conjunto de erros nas previsões dos modelos atuariais da previdência. Esses autores, analisando a precisão e a metodologia dos instrumentos utilizados pelo governo brasileiro para construir as previsões atuariais da previdência, constataram diversos erros entre os valores previstos e realizados para a receita, despesa e déficit do sistema previdenciário para a maioria dos anos entre 2002 a 2015. Essas previsões atuariais e financeiras pautam as principais reformas previdenciárias que foram implementadas no Brasil, incluindo a Reforma da Previdência do atual governo Bolsonaro. Segundo esses autores, essas falhas subestimam as receitas e superestimam os gastos previdenciários, construindo um quadro equivocado da real situação da previdência.

Diante desses elementos, o objetivo deste artigo é analisar o Regime Geral da Previdência no Brasil, aprofundando essas análises não convencionais sobre a previdência, focando especialmente na dinâmica previdenciária, na razão de dependência e no custo macroeconômico. Para alcançar esse objetivo, além dessa introdução e da conclusão, esse artigo está dividido em mais três seções. Na segunda seção é realizada uma descrição da dinâmica das transferências governamentais feitas para o sistema previdenciário e do comportamento do resultado previdenciário no período entre 1994-2017. Essa análise busca trazer evidências de como a dinâmica previdenciária se relaciona com um conjunto de outras variáveis como a estrutura e dinâmica do mercado de trabalho brasileiro. Na terceira seção, seguindo a contribuição de Paley (1998) e Yasar (2012), é apresentado um indicador de sustentabilidade do sistema previdenciário brasileiro, com base em um cálculo da razão de dependência não convencional, que incorpora a produtividade e a informalidade. Na quarta seção, expandindo as possibilidades de avaliação do sistema previdenciário brasileiro, é feito um cálculo do custo macroeconômico da previdência com base em Thompson (1998).

\section{Dinâmica previdenciária: uma análise para o período 1994-2017}

A discussão sobre a dinâmica do sistema previdenciário é fundamental para identificar quais as variáveis são mais importantes para entender o seu comportamento. Nesse sentido, a presente seção fornece uma análise da dinâmica do Regime Geral da Previdência no Brasil (RGPS), analisando dois aspectos: as transferências do governo e o resultado previdenciário, esse último com base em 
duas diferentes metodologias: a primeira considera as receitas totais, o que inclui os repasses da União, e a segunda pressupondo apenas as receitas advindas das contribuições. Os dados analisados para o Sistema Previdenciário brasileiro nessa seção são compilados apenas para o Regime Geral da Previdência (RGPS) e cobrem o período entre 1993 até 2017. Todos eles foram consultados a partir do Anuário Estatístico da Previdência - Suplemento Histórico, que tem como base primária os dados do MTPS/DATAPREV/INSS, deflacionadas para o período 2017 com base no Índice Nacional de Preços ao Consumidor (INPC).

\subsection{Transferências da União}

De um modo geral, as principais receitas previdenciárias brasileira podem ser divididas em dois grandes grupos ${ }^{1}$ : as Receitas Correntes e as Transferências ou Repasses da União. Nas receitas correntes estão todas as receitas oriundas de contribuições, com destaque para aquelas provenientes dos Segurados, das Empresas, a Contribuição sobre a Produção Rural, o Simples Nacional ${ }^{2}$ e a Contribuição Previdenciária dos Órgãos do Poder Público ${ }^{3}$. O segundo grupo, Transferências da União (TU), é composto por tributos que tem parte das suas receitas destinada para o financiamento da seguridade social, como a Contribuição sobre o Lucro das Empresas (CSLL) e o Fundo de Investimento Social (FINSOCIAL). Enquanto as receitas correntes têm suas alíquotas definidas por lei, não há uma definição legal do percentual dos impostos que deve ser destinado a Previdência Social, fazendo com que esses valores variem ao longo do tempo.

Com base na forma em que o sistema de contribuições da previdência brasileira está organizado, as Receitas Correntes ou Contribuições $\left(C_{t}\right)$ são uma função das seguintes variáveis: o número de trabalhadores ativos e contribuintes $\left(L_{t}\right)$, a média da taxa do salário real $\left(w_{t}\right)$, a taxa de contribuição $\left(r_{t}\right)$ em um

\footnotetext{
${ }^{1}$ Além desses dois grandes grupos, também há nas receitas previdenciárias alguns recursos que advém de tributos, de serviços, patrimonial, mas que proporcionalmente tem pouco peso no total das receitas previdenciárias e que por isso não serão analisadas aqui.

${ }^{2}$ O Simples Nacional é um regime compartilhado de arrecadação, cobrança e fiscalização de tributos aplicável às Microempresas e Empresas de Pequeno Porte, previsto na Lei Complementar nº 123, de 14 de dezembro de 2006. Tal regime institui uma cobrança diferenciada para um conjunto de impostos que são destinados a Seguridade Social, tais como: CSLL, Confins e a Contribuição para a Seguridade.

3 Aqui é importante não confundir com a contribuição patronal feita pelos órgãos públicos para os servidores que estão submetidos ao Regime Próprio da Previdência (RPPS). Nesse caso, trata-se de um conjunto de contribuições previdenciárias a serem recolhidas junto ao INSS, tais como, o desconto dos $11 \%$ dos contribuintes individuais, $11 \%$ do valor bruto da nota fiscal das empresas prestadoras de serviços de cessão de mão de obra e empreitada. Além disso, também entra o desconto das contribuições dos servidores públicos não vinculados a RPPS.
} 
particular ano $(t)$, ou $C_{t}=L_{t} w_{t} r_{t}$. Já as Transferências da União $\left(T U_{t}\right)$ irão depender de um percentual $(\alpha)$ dos tributos utilizados para financiar o Orçamento da Seguridade Social $\left(a_{t}\right)$ e da sua base de incidência, que, aqui, por simplificação, será considerado o Produto (PIB) da economia como um todo (Y), ou $T U_{t}=$ $\alpha a_{t} Y_{t}$. Assim, o total das receitas previdenciárias $\left(R_{t}\right)$ é o somatório das Transferências da União $\left(T U_{t}\right)$ e das Contribuições $\left(C_{t}\right)$ em um determinado ano.

$$
\begin{gathered}
R_{t}=T U_{t}+C_{t} \\
R_{t}=\alpha a_{t} Y_{t}+L_{t} w_{t} r_{t} .
\end{gathered}
$$

No debate político sobre a Previdência no Brasil, o principal argumento utilizado para resolver o problema do aumento crescente dos déficits da previdência é através de instrumentos que reduzam as despesas e os que ampliem as receitas apenas pelo aumento das contribuições. Isso foi bem observado nos debates que fundamentaram as mudanças trazidas pela Reforma da Previdência através da Emenda Constitucional 103 (EC 103). Pelo desenho da reforma, observa-se um excesso de preocupação em ampliar as contribuições dos trabalhadores, através do aumento das alíquotas, ao mesmo tempo em que são reduzidos os ganhos no momento da aposentadoria, ampliação da idade mínima e do tempo de contribuição, de modo a garantir o desejado equilíbrio fiscal da previdência.

Há por parte de diversos setores da sociedade que defendem uma redução das despesas previdenciárias a qualquer custo uma insistência em transmitir a ideia de que a insustentabilidade do sistema está associada ao aumento descontrolado dos gastos. Todavia, pouco se fala do conjunto de possibilidades de melhorar as contas da previdência através de outros instrumentos nas receitas, de modo a manter o desenho atual dos benefícios. Partindo da Equação 2, para ampliar as receitas previdenciárias existem seis instrumentos, três pelo lado das contribuições - o número de trabalhadores ativos e contribuintes, a média da taxa do salário real e a taxa de contribuição - e três pelas transferências - o percentual dos tributos, o Orçamento da Seguridade Social e o PIB. Neste trabalhado são explorados os instrumentos ligados às transferências.

No período da promulgação da Carta Magna, uma massa de trabalhadores idosos brasileiros estava completamente destituída do acesso à previdência, sendo a causa dessa exclusão a própria característica do mercado de trabalho brasileiro e 
o modo de inserção desses trabalhadores ao longo do seu histórico laboral. Essa foi uma das justificativas para se criar um conjunto de impostos para auxiliar o financiamento do sistema previdenciário para além das alíquotas pagas pelos contribuintes. Contudo, nos últimos anos observa-se um aumento da participação dessas transferências na complementação das receitas da previdência, o que tem gerado preocupações por parte das autoridades governamentais.

O Gráfico 1 mostra a evolução dos Repasses do Governo durante o período a partir de dois indicadores. No lado esquerdo está a participação dessas transferências no total das receitas $(T U / R P)$ e o lado direito mede a proporção desses gastos em relação ao PIB (TU/PIB). Independente da metodologia usada, é evidente um aumento expressivo na participação do governo na complementação das receitas previdenciárias nos últimos anos.

\section{Gráfico 1 - Transferências da União para o RGPS como participação das Receitas Totais e Participação no PIB (\%)}

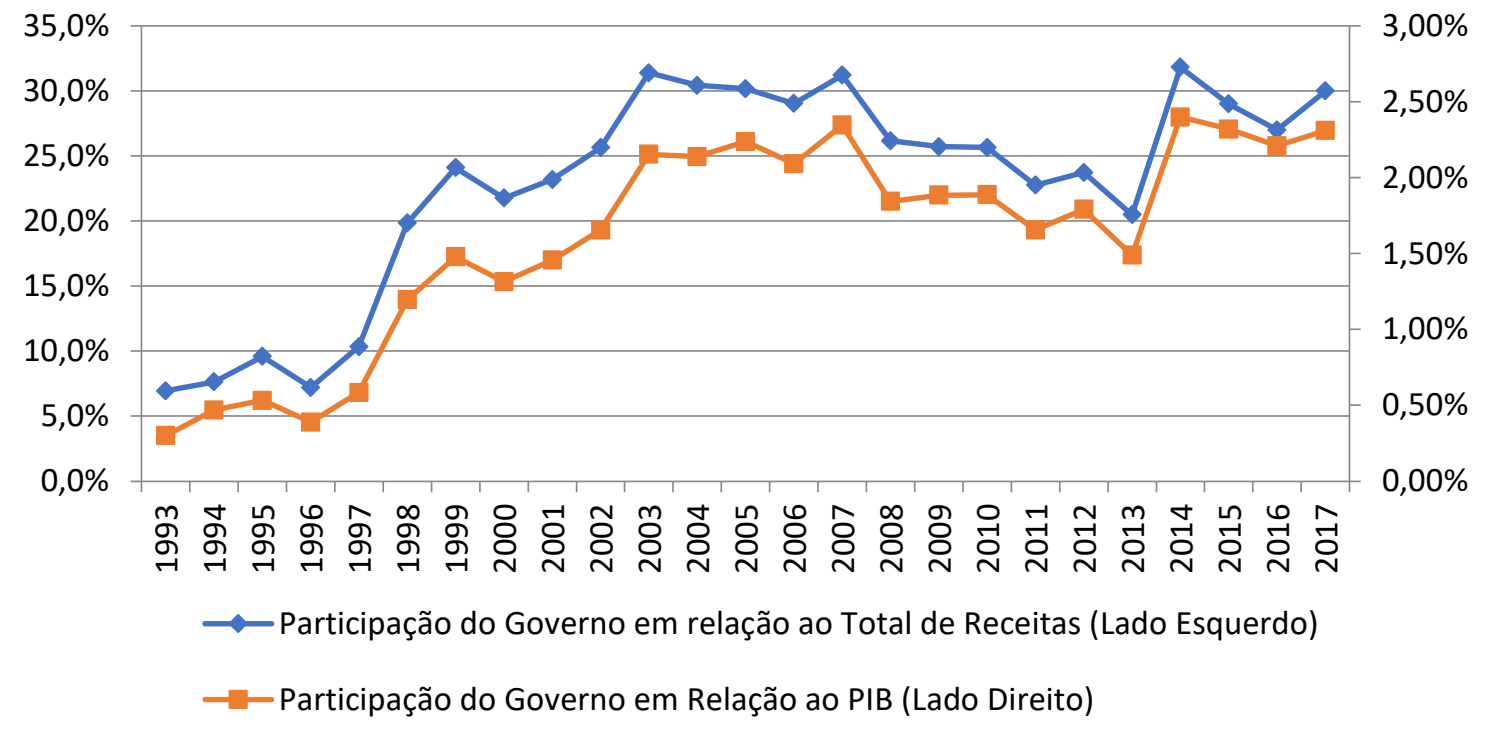

Fonte: elaboração própria com base nos dados do MTPS/DATAPREV/INSS e IPEADATA.

Como se pode observar no lado esquerdo do Gráfico 1, até 1997 a participação da União no Total das Receitas Previdenciárias foi de no máximo 10\% em 1995, sendo decrescente em alguns momentos, como entre 1995 a 1996. A partir desse momento, essa participação teve um crescimento contínuo, com a elevação mais significativa entre 1997 a 1999, quando a participação das transferências da União aumentou quase $150 \%$, saindo de aproximadamente $10 \%$ 
para $25 \%$ do total das receitas previdenciárias. Entre 2003 a 2007, ela permaneceu relativamente estável, apesar de apresentar os níveis históricos mais elevados (cerca de 30\%). A partir de então as transferências da União passaram a cair, alcançando em 2013 os mesmos patamares de 2001, aproximadamente 17\% das Receitas Totais eram compostas por Transferências da União. Em 2014, as transferências subiram novamente para os maiores patamares de toda a série.

Apesar de ser um indicador importante para medir a dimensão da necessidade que o RGPS brasileiro tem das transferências governamentais, a Participação das Transferências da União em relação ao Total das Receitas possui limitações. Uma delas é que nem sempre alterações na participação das transferências da União nas receitas da Previdência representam mudanças na mesma proporção do montante transferido. Assim, mesmo que a União dobre a sua participação nas receitas previdenciárias, isso não significa que ela passou a injetar o dobro dos recursos no sistema. Isso porque, como o indicador é uma razão entre Transferências do Governo e o Total das Receitas (contribuições mais transferências) $(T U / R P)$, uma mudança nos patamares de participação da União também é influenciada por mudanças nos níveis de receitas de contribuição, que terminam por modificar a participação relativa da União, sem necessariamente terem sido alterado os montantes transferidos. Nesse sentido, um segundo indicador também é apresentado, mas agora no lado direito do Gráfico 1, que é a Participação das Transferências no total do PIB (TU/PIB).

Segundo Matos, Melo e Simonassi (2013), esse último indicador é mais apropriado para analisar a solvência do RGPS porque ele consegue medir de forma mais precisa a dimensão da participação governamental. Com base nesse indicador, é possível perceber se os gastos do governo para complementar a previdência possuem um comportamento explosivo do ponto de vista macroeconômico. Nesse caso, mesmo que a existência de sucessivos déficits seja um sinal de alerta e preocupação por parte da sociedade, se a participação governamental neste regime se mantém constante ou em queda, apesar de não anular a necessidade de reformas, redimensiona qual o real problema do sistema.

De uma maneira geral, o movimento desse indicador segue uma tendência parecida do primeiro indicador $(T U / R P)$, como observado ainda no Gráfico 1 . Novamente, alguns elementos chamam atenção nesse gráfico. O primeiro deles é que entre 2013 e 2014 as Transferências da União para o RGPS como uma 
proporção do PIB praticamente dobraram, saindo de 1,49\% para 2,77\%, uma elevação de quase $87 \%$. Além de ser um aumento significativo para um período tão curto, apenas um ano, se analisarmos exatamente o período anterior, entre 2007 e 2013, essas transferências estão caindo sistematicamente, saindo de um patamar de 2,35\% do PIB para 1,49\% em 2013, uma queda de quase 37\%. Além disso, entre 2002 a 2007, mesmo havendo um leve movimento de crescimento, ele esteve em média no patamar $2,1 \%$ do PIB. Como argumentado na subseção anterior, o aumento significativo dos gastos da União com a Previdência entre 2013 e 2017 está relacionado com a queda nas receitas da previdência advindas das empresas (contribuições patronais), que pode ter sido consequência da política de desoneração fiscal no período.

A elevada participação da União na complementação das receitas previdenciárias é um importante argumento em prol de reformas que tornem a previdência menos dependente dessas transferências e mais capaz de se autofinanciar a partir dos seus contribuintes. Contudo, essas variações, em um período tão curto de tempo, não podem ser explicadas apenas pela ampliação das despesas, ou pelo processo de transição demográfica que o país começa a enfrentar. A elevação dos benefícios gerada pela política de valorização salarial executada nos últimos anos, como argumentado em alguns trabalhos que analisam o sistema previdenciário brasileiro, também não explicaria essa mudança de um ano para o outro. Ao que tudo indica, as causas para a ampliação dessa participação não têm como único fator o aumento dos gastos no RGPS.

Não se pode negar que, desde 2014, tem havido um aumento do peso das transferências da União para a previdência. Contudo, como argumentado anteriormente, essa participação se manteve estável ou em queda até 2013. Do ponto de vista da reforma previdenciária brasileira, uma das questões que se coloca é saber qual o patamar de Transferências da União para complementar as receitas da previdência? Pode-se argumentar que essas transferências devem tender a zero, isto é, o sistema previdenciário precisa se sustentar apenas com as suas receitas. Do ponto de vista estritamente atuarial, esse argumento se justifica já que ele garante a sustentabilidade do sistema no médio e longo prazo, contudo ele é limitado, pois não considera o papel que a previdência desempenha tanto do ponto de vista social quanto econômico. Nesse caso, ao invés de transferências que tendam a zero, pode- 
se construir uma proposta que busque garantir uma trajetória sustentável para esses gastos, de modo a garantir direitos sem penalizar as contas públicas.

\subsection{O resultado previdenciário}

De um modo geral, o Resultado Previdenciário é calculado com base na diferença entre as receitas e despesas previdenciárias. $\mathrm{O}$ grande problema é que, como existem diferentes fontes de receitas e despesas, é possível utilizar mais de um critério para definir qual o resultado para a Previdência (Gentil, 2006; Puty et al., 2017). Nessa subseção, apresentam-se duas das principais formas para calcular esse resultado no Brasil, e as limitações e vantagens de se utilizar cada uma delas.

O Gráfico 2 exibe os resultados encontrados a partir dessas duas abordagens. A primeira, indicada pela linha azul, utiliza os valores das Despesas Totais e das Receitas Totais que inclui, além das contribuições, as transferências da União. Cabe destacar que o cálculo não é feito como no trabalho de Gentil (2006). Nele, a autora incorpora nas receitas da previdência uma estimação dos valores de impostos que fazem parte do Orçamento da Seguridade Social, mas que não foram utilizados por causa do instrumento de Desvinculação das Receitas da União (DRU). Diferente dessa abordagem, no cálculo das Transferências utilizadas aqui, são incluídos apenas os valores do Orçamento da Seguridade que foram efetivamente utilizados pela Previdência.

Com base nessa metodologia, durante o período entre 1993 a 2017 ocorreu déficit em nove anos: 2003 (R\$ 828 milhões), 2006 (R\$ 18 bilhões), 2008 (R\$ 2,065 bilhões), 2009 ( $\mathrm{R} \$$ 8,647 bilhões), 2013 ( $\mathrm{R} \$ 12,622$ bilhões), 2014 ( $\mathrm{R} \$$ 18,879 bilhões), 2015 ( $\mathrm{R}$ \$ 7,607 bilhões), 2016 ( $\mathrm{R} \$ 20,364$ bilhões) e 2017 ( $\mathrm{R} \$$ 11,068 bilhões). Em uma parte do tempo, o sistema está em quase equilíbrio (indicado pela linha azul próxima ao eixo da abscissa), indicando que o total das receitas foi suficiente para cobrir as despesas. Esses resultados colocam em questionamento o amplo argumento político e midiático de que o sistema previdenciário brasileiro está em crise desde a sua origem. Contudo, esse indicador é limitado para demonstrar a sustentabilidade fiscal e financeira do sistema previdenciário brasileiro, já que ele considera outras receitas além daquelas pagas pelos contribuintes. Assim, a maior parte dos analistas da previdência, geralmente, não utiliza essa metodologia como instrumento para verificar a sustentabilidade financeira e atuarial do sistema. Ao se excluir as fontes de financiamento vindas 
do Orçamento da Seguridade, os resultados do Regime Geral ao longo do tempo passam a ser diferentes.

\section{Gráfico 2 - Resultado previdenciário brasileiro (milhões R\$)}

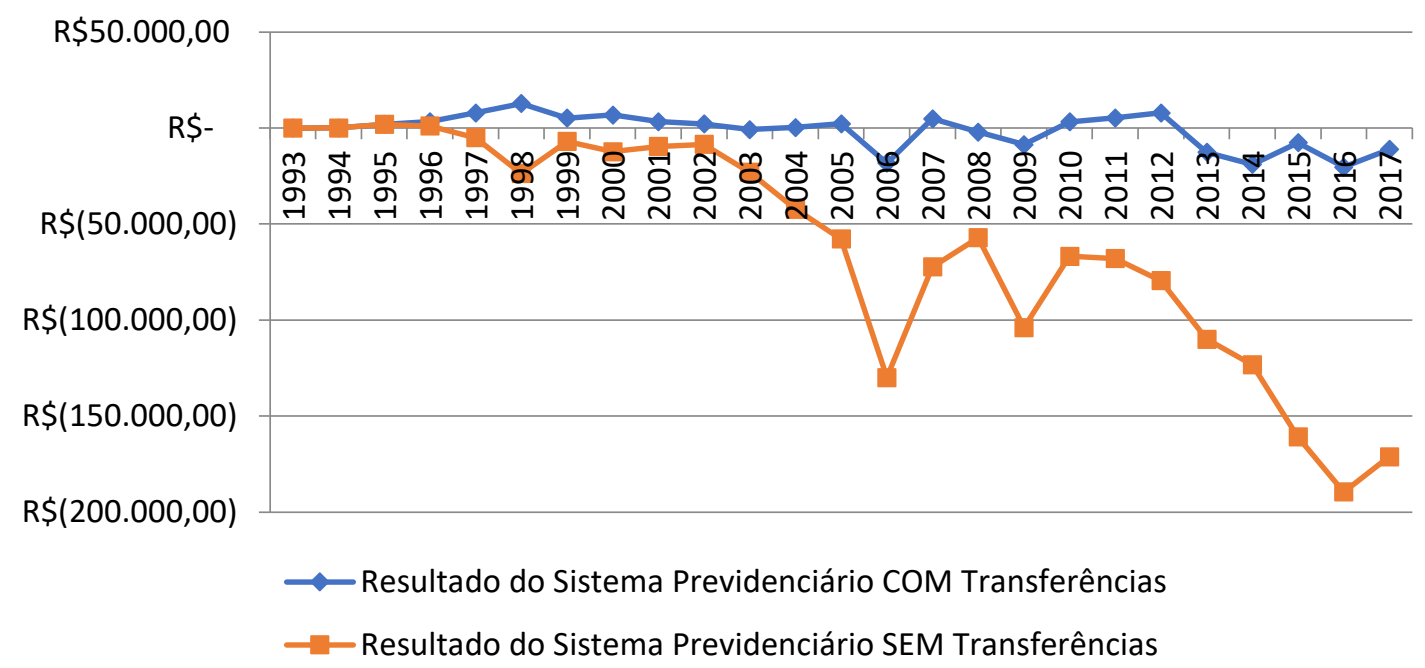

Fonte: elaboração própria com base nos dados MTPS/DATAPREV/INSS.

Do ponto de vista do equilíbrio atuarial e financeiro, a segunda metodologia, que exclui as transferências da União, é mais coerente para analisar o sistema previdenciário. Isso porque ela observa nas receitas apenas o que vem das contribuições (Receitas Correntes), retirando dela os repasses governamentais. No Gráfico 2, a linha vermelha mostra o comportamento do resultado previdenciário ao longo do período de análise seguindo essa segunda metodologia. Nos anos iniciais da série, as duas metodologias apresentam resultados próximos entre si. Contudo, a partir de 1996, o regime previdenciário passou a apresentar sucessivos déficits. Essa situação se torna ainda mais complexa a partir de 2002, quando o déficit da previdência com base nessa metodologia passa a se ampliar significativamente. O principal fator que explica a diferença nesses dois resultados é o aporte anual de transferências de recursos da União. Essa necessidade de financiamento vindo do governo Federal é um dos principais argumentos sobre a necessidade de reforma do sistema, pois é insustentável manter essas transferências em patamares elevados ou crescentes de modo indefinido.

Apesar de reconhecer como um sinal de fragilidade da previdência essa ampliação da dependência do sistema das Transferências da União em detrimento das contribuições, é fundamental não se perder de vista os princípios 
constitucionais que regem o sistema previdenciário. Desde a promulgação da $\mathrm{CF}$ já se previa que o total das contribuições poderia não ser capaz de cobrir o total das despesas, dado a necessidade de garantir a cobertura previdenciária para uma grande massa de trabalhadores idosos que não haviam conseguido contribuir o suficiente. Para resolver esse problema foram criados alguns impostos, em destaque para o CSLL e o FINSOCIAL, com o objetivo de garantir a sustentabilidade do sistema.

Essas transferências do governo federal para a previdência revelam uma característica essencial do sistema previdenciário brasileiro, definido no próprio texto constitucional (art. $3^{\circ}$, I, e art. 195, caput da CF/88) que é o da solidariedade. Havia um entendimento no momento em que a CF foi elaborada que aqueles indivíduos que detinham melhores condições econômicas deveriam contribuir com uma parcela maior de sua renda para a Seguridade Social, o que inclui, além das contribuições previdenciárias, o pagamento de impostos para o financiamento da seguridade social ${ }^{4}$. Os impostos utilizados para financiar a previdência auxiliam no cumprimento desses princípios constitucionais, não podendo ser analisados apenas em uma perspectiva fiscal.

Alguns fatos chamam a atenção ao se analisar o comportamento das receitas durante esse período. Na maior parte dele, a arrecadação apresentou certa estabilidade. Porém, alguns períodos registram uma queda significativa nas receitas previdenciárias, como entre os anos de 2013 e 2014. Analisando os dados, há evidências de que o principal responsável pela diminuição da arrecadação nesse período foi a queda nas contribuições das empresas, o que pode ser explicado pela política de desonerações fiscais realizadas no Brasil ${ }^{5}$ (Gentil, 2017).

Nos últimos anos, a discussão sobre a desoneração da folha de pagamentos tem sido um tema recorrente no debate político nacional, sendo que desde o final da década de 1990 diversas medidas na forma de leis e emendas constitucionais foram tomadas no sentido de reduzir a tributação em alguns setores econômicos (Paiva; Ansiliero, 2009). Há explicitamente um entendimento de que os altos

\footnotetext{
${ }^{4}$ Por outro lado, aqueles com menores condições de contribuição, apesar de permanecerem obrigados a contribuir (princípio da Contributividade) poderiam participar com menos.

${ }^{5}$ Outro fator que auxilia a explicar a redução das contribuições das empresas é a sonegação fiscal. Segundo o Instituto Brasileiro de Planejamento e Tributação (IBPT, 2009), a contribuição das empresas para o INSS é o tributo com maior índice de sonegação. Contudo, para associar a queda da contribuição nesse período com o aumento da sonegação fiscal seria necessária uma análise aprofundada dos dados para esse período, de modo a verificar se houve nesses anos um aumento relativo da sonegação.
} 
índices de informalidade no país, e seu consequente impacto sobre a arrecadação previdenciária, está diretamente relacionado à tributação sobre a folha de salários. Assim, os principais efeitos esperados da desoneração seriam a diversificação das bases de arrecadação da previdência e a geração de postos formais (NERI, 2007), além de estimular o investimento e melhorar as condições de competitividade nacional (Gentil, 2017). Mas há evidências que essa política tributária não tem conseguido alcançar esses objetivos, podendo gerar até efeitos inversos daqueles esperados (Ansiliero et al., 2008; Gentil, 2017).

Os principais trabalhos que apresentam algum (relativo) suporte empírico acerca do impacto da desoneração sobre a formalização da mão de obra, como Neri et al. (2007), Bordonaro (2003), Ulyssea e Reis (2006), só conseguem chegar às suas conclusões em um cenário em que a desoneração é total. Sendo que, mesmo nessa situação extrema, o impacto é modesto. Segundo Paiva e Ansiliero et al. (2009), o problema nos modelos desenvolvidos nesses trabalhos é que eles pressupõem que a informalidade é resultado de uma escolha das empresas e dos trabalhadores com base em uma avaliação do custo/benefício da filiação previdenciária. Contudo, observando a economia brasileira, o que se percebe é uma profunda segmentação entre os setores formal e informal do mercado de trabalho (Barros et al., 2007), de maneira a formar dois mercados com regras próprias, apesar de existir um conjunto de atividades que estejam no limiar dos dois mercados. Como consequência, há uma menor mobilidade dos trabalhadores entre os segmentos, o que limita o argumento de que a escolha pela formalização é uma opção do trabalhador e que as desonerações seriam um incentivo para a formalização.

Assumindo-se que a informalidade é uma consequência da segmentação do mercado ao invés de "escolhas racionais dos agentes econômicos", estratégias específicas visando atingir o setor informal poderiam gerar maiores efeitos sobre a contribuição previdenciária e o grau de formalização do que a desoneração na folha de pagamentos (Paiva; Ansiliero, 2009). Nesse sentido, apoio técnico, linhas de crédito especiais, investimento em qualificação, entre outros, são instrumentos mais eficientes para ampliar a formalização dos pequenos e médios empreendimentos informais, bem como dos trabalhadores autônomos, do que uma política de desoneração da folha de pagamentos (Paiva et al., 2009). 


\section{Razões de dependência previdenciária}

Além da dinâmica das receitas e despesas e o papel desempenhado pelas transferências da União, outro instrumento que ajuda a entender a condição do sistema de Previdência de um país é a Razão de Dependência Previdenciária (RDP). Através desse indicador é possível avaliar a forma como o sistema previdenciário é impactado pelo envelhecimento populacional. Contudo, há algumas limitações no modo convencional como esse indicador é calculado. Nesse sentido, o objetivo dessa seção é, em um primeiro momento, apresentar o índice convencional para calcular a razão de dependência, e, em segundo lugar, além de apresentar as limitações do índice convencional, fazer algumas alterações de modo a ampliar o seu poder analítico.

\subsection{Razão de dependência previdenciária "convencional"}

O envelhecimento da população é um dos principais argumentos em favor de reformas na previdência. Os principais organismos multilaterais, como o Banco Mundial e o FMI, elegeram a transição demográfica como o grande responsável pela crise fiscal, que fragiliza as finanças públicas com impactos diretos sobre o crescimento econômico. Tratando-se do Brasil, segundo dados do IBGE (2016), a população jovem, de zero a 14 anos, após o ano 2000, começou a diminuir em termos absolutos enquanto a população idosa, com mais de 65 anos, a partir de 2010, acelerou o seu crescimento. De acordo com as projeções, essa tendência nesses dois grupos levaria a população idosa a ultrapassar os jovens entre 2030 e 2040. Concomitante a isso, o maior grupo populacional, o adulto, entre 15 e 64 anos, manteria o seu crescimento absoluto até a década de trinta desse século, começando a diminuir o seu tamanho absoluto a partir desse período. Apesar do Brasil ainda viver uma fase de crescimento populacional que constitui uma janela de oportunidades, esses dados e projeções indicam uma aceleração no processo de transição demográfica no Brasil, o que gera vários desafios econômicos, sociais e políticos para a sociedade brasileira.

Os impactos dessa mudança demográfica são diversos. Do ponto de vista de ação do Estado, ela impõe uma reformulação em diversas políticas públicas. Países que ainda convivem com um boom populacional, em geral, terão mais gastos nas áreas de educação, cuidados e saúde infantil. Por outro lado, populações 
em envelhecimento tendem a demandar outras políticas públicas focadas nas populações mais velhas, incluindo a previdência.

Tratando-se da sociedade brasileira, essas mudanças demográficas têm um grande potencial de ampliar os gastos previdenciários, porém, o aumento nos déficits da previdência não possui necessariamente relação com esse processo. Não há dúvidas que, no longo prazo, o envelhecimento populacional pressiona as contas da previdência, mas isso não significa que os resultados que a previdência já vem apresentando são uma consequência da mudança demográfica, como argumentado em alguns trabalhos. Uma forma de avaliar melhor essa questão é através da Razão de Dependência Previdenciária (RDP).

De modo geral, a RDP é calculada a partir da razão entre a massa de trabalhadores contribuintes e a população que recebe benefícios (aposentados, pensionistas e beneficiários). Apesar de refletir a transição demográfica de uma dada sociedade, a RDP é também influenciada por outros fatores não demográficos. Segundo Beltrão (1995), o total de contribuintes é determinado por dois fatores em especial: a participação da População Economicamente Ativa (PEA) na População em Idade Ativa (PIA) e o grau de formalização das relações de trabalho. Já a população beneficiária depende de fatores demográficos como a expectativa de vida e da legislação previdenciária. Ela pode ser representada da seguinte forma: $R D P=\frac{\text { Beneficiários }}{\text { Contribuintes }}$.

Com base nesse indicador é possível verificar o comportamento da participação relativa do contingente populacional de beneficiários que é sustentado pela parcela da população ativa contribuinte. Sendo útil como instrumento para acompanhar o grau de dependência econômica em uma determinada população bem como para subsidiar a formulação de políticas nas áreas de saúde e de previdência social.

No Gráfico 3, observa-se o comportamento da RDP no Brasil entre o período de 1992 a 2016. Percebem-se três fases distintas. Na primeira, entre 1992 a 1999, houve um aumento significativo nessa razão, saindo de 0,35 para 0,5. Depois de um curto período de estabilidade (2000-2003), há uma segunda fase até 2012 em que o índice teve uma queda e, por fim, uma terceira fase mais recente, em que ele voltou a se elevar. Se essas mudanças estivessem relacionadas com fatores exclusivamente demográficos, era de se esperar que variáveis ligadas à demografia, como mortalidade infantil e expectativa de vida, também tivessem 
mudado nesse período. Contudo, como argumentado por Brito (2017), no que se referem a tendências demográficas, intervalos de tempo abaixo de 30 anos nem sempre apresentam mudanças demográficas significativas, como é o caso do Brasil. Considerando que as variáveis demográficas não se alteraram significativamente nesse período, entre 1992 a 2016 há evidência de que foram os fatores ligados à dinâmica macroeconômica e suas repercussões sobre o mercado de trabalho brasileiro que afetaram a RDP, e não os fatores demográficos.

\section{Gráfico 3 - Razão de dependência previdenciária (1992-2017)}

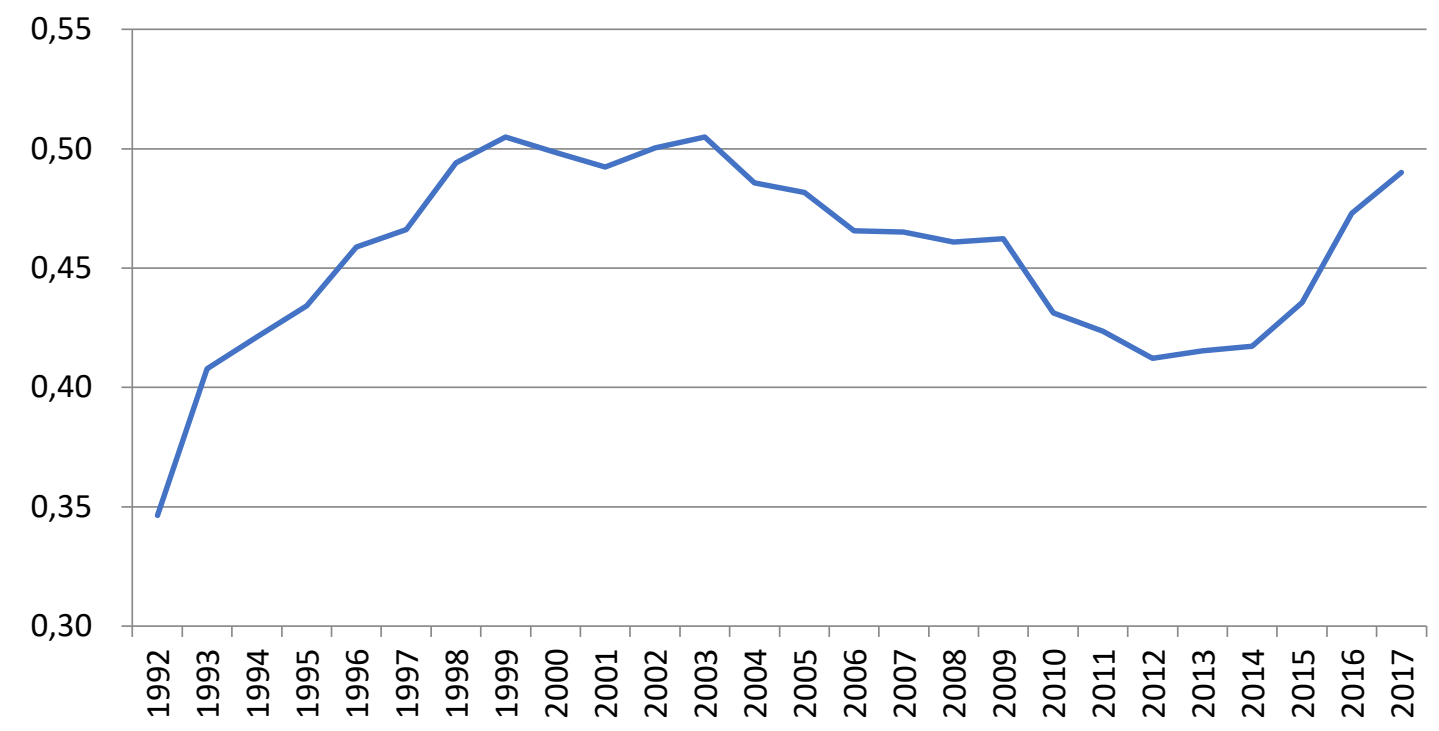

Fonte: elaboração própria com base nos dados do IPEADATA com base na PNAD/IBGE.

Os períodos de aumento nesse indicador (1992-1999 e a partir de 2013) correspondem também aos momentos de piora nas condições de trabalho no Brasil, e a consequente deterioração nos índices de desocupação e informalidade. Por outro lado, a fase que o indicador apresente queda (2003-2012) coincide com o mesmo momento que a economia brasileira vivenciou um aumento no crescimento econômico e redução na informalidade. Esse crescimento do PIB pode ter afetado direta e positivamente o número de contribuintes, via aumento do emprego (Lei de Okun) e, consequentemente, da RDP. Contudo, o crescimento do PIB só consegue melhorar as contas da previdência via aumento do emprego quando esse emprego gerado é ocupado por trabalhadores contribuintes, sejam eles formais, autônomos ou por conta própria. Nesse sentido, há evidência que no curto prazo, os fatores ligados à dinâmica do mercado de 
trabalho são mais relevantes para entender o movimento da razão de dependência previdenciária do que os fatores demográficos.

Outro fator a destacar com base no Gráfico 3 é que a Previdência Social pode ter atuado como um estabilizador automático para a economia. Há sinais de que nos momentos de menor crescimento econômico no Brasil (durante a década de 1990 e a partir de 2013), há um aumento da RDP, indicando uma ampliação nos gastos previdenciários. Por outro lado, nos momentos de maior crescimento, a RDP reduz. Assim, além de refletir a dinâmica do mercado de trabalho brasileiro no período, a previdência também pode ter atuado indiretamente como um instrumento de estabilização dos ciclos econômicos no Brasil.

Segundo Rocha (2009), os estabilizadores fiscais automáticos podem ser definidos como o conjunto de receitas e despesas do governo que reagem automaticamente a mudanças na atividade econômica. Dessa forma, eles reduzem a magnitude dos ciclos, estimulando a economia nos momentos de recessão ou desestimulando nos tempos de expansão. Uma forma de avaliar os estabilizadores automáticos é decompondo o saldo orçamentário em um componente estrutural e um componente cíclico ${ }^{6 s}$. O componente estrutural é obtido com uma função dos desvios do produto observado e do produto potencial e está relacionado estritamente às medidas discricionárias de política fiscal. Já o componente cíclico é encontrado aplicando ao hiato do produto as chamadas elasticidades fiscais, que medem os efeitos do produto sobre o saldo orçamentário fiscal.

Melo e Mocero (2006), utilizando essa metodologia, tentam identificar o componente cíclico para o Brasil no período entre 1995 a 2005. Para isso, eles calculam as elasticidades de transferências e impostos com relação às flutuações econômicas de quatro itens de receita, incluindo as contribuições previdenciárias e um item das despesas. A elasticidade estimada gira em torno de 0,32 para a economia brasileira no período de 1995-2005. Isso significa que o aumento de um ponto percentual do hiato do produto aumenta o superávit cíclico (ou reduz o déficit cíclico) em $0,32 \%$ do produto. Esse resultado é menor do que a média calculada para a OCDE $(0,44)$, mas é similar ao calculado para os EUA $(0,34)$ e

\footnotetext{
${ }^{6}$ Essa metodologia pode ser vista como algo análogo a Regra de Taylor, mas ao invés de aplicada à política monetária ela é utilizada para a política fiscal (ROCHA, 2009). Nesse caso, a regra de política fiscal assume a seguinte forma: $d_{t}=\mu_{t}+\alpha v_{t}$, onde $d_{t}$ é o saldo orçamentário efetivo como proporção do PIB, $\mu_{t}$ é o saldo orçamentário estrutural, $v_{t}$ é o desvio do produto efetivo em relação ao potencial, o que faz com que $\alpha v_{t}$ seja o componente cíclico do saldo orçamentário efetivo, que aparece no momento em que ocorre flutuações no produto.
} 
Japão (0,33). Assim, em relação aos países da OCDE, os estabilizadores automáticos no Brasil desempenham um papel menos importante na explicação do saldo fiscal ao longo do ciclo econômico, mas ainda assim relevante. Como o exercício é feito para um conjunto de receitas, não é possível isolar o impacto específico da previdência sobre o ciclo econômico, algo que pode ser explorado em outros trabalhos.

\subsection{Razão de dependência previdenciária alternativa}

Apesar de seu potencial analítico, em diversos contextos econômicos e sociais, a Razão de Dependência Previdenciária acaba por não refletir a capacidade potencial que uma estrutura populacional tem de garantir a sustentabilidade do seu sistema previdenciário. Altos índices de desemprego e informalidade contribuem para o enfraquecimento da previdência. Porém, eles não estão refletidos nessa razão de dependência tradicional. Diante disso, seguindo Paley (1998) e Yasar (2013), essa seção propõe uma alternativa para a RDP que é a Razão de Dependência Econômica Efetiva (RDEE). Nela, busca-se incorporar no cálculo outras variáveis ausentes na RDP, e pode ser representada da seguinte forma: $R D E E=\frac{\text { População Inativa Efetiva }}{\text { População Ocupada Efetiva }}=\frac{E_{t}}{N_{t}}$.

A primeira diferença para a RDP é que nessa nova Razão de Dependência não se considera apenas os beneficiários da previdência, mas toda a população inativa. Nesse caso, também entram no cálculo os indivíduos que não podem trabalhar, seja por idade (inclusive crianças) ou por incapacidade, mesmo que não recebam nenhum tipo de benefício previdenciário. Outra diferença importante é que agora não se considera apenas os trabalhadores que contribuem para a previdência, mas toda a população ocupada, o que inclui os trabalhadores autônomos e informais não contribuintes. Por fim, a terceira diferença é que na Razão de Dependência Econômica Efetiva (RDEE) se incorpora o crescimento da produtividade do trabalho. Essa é, portanto, uma medida da população economicamente inativa e de população ocupada ajustada pelo aumento da produtividade.

O número de população ocupada efetiva é obtido da seguinte forma:

$$
N_{t}=[1+n+g] N_{t-1}
$$


Onde $N_{t}$ é o trabalhador efetivo, (n) é a taxa de crescimento populacional e (g) a taxa de crescimento da produtividade. Já o número de beneficiários efetivos $\left(E_{t}\right)$ é calculado como segue:

$$
E_{t}=E_{t-1}+r[1+g] P_{t-1}
$$

Em que (r) é a taxa de crescimento dos aposentados, $P_{t-1}$ número atual de trabalhadores.

Os resultados são apresentados no Gráfico 4. Nele se observa que mesmo essa nova razão de dependência tendo iniciado em valores elevados, ela possui uma inclinação negativa, o que indica haver uma tendência de queda em toda a série analisada, a exceção do período entre 1995 e 1996. Até 2004, a despeito da tendência de redução, os valores acima de 1 apresentados no índice demonstram que a População Ocupada Efetiva no Brasil era proporcionalmente inferior a População Inativa Efetiva. Isso significa que até esse período cada trabalhador efetivo precisava "sustentar" economicamente mais de uma pessoa que estava na inatividade. Apenas a partir de 2004 é que o número proporcional de trabalhadores efetivos passou a superar o da população inativa.

\section{Gráfico 4 - Razão de Dependência Econômica Efetiva (1992-2017)}

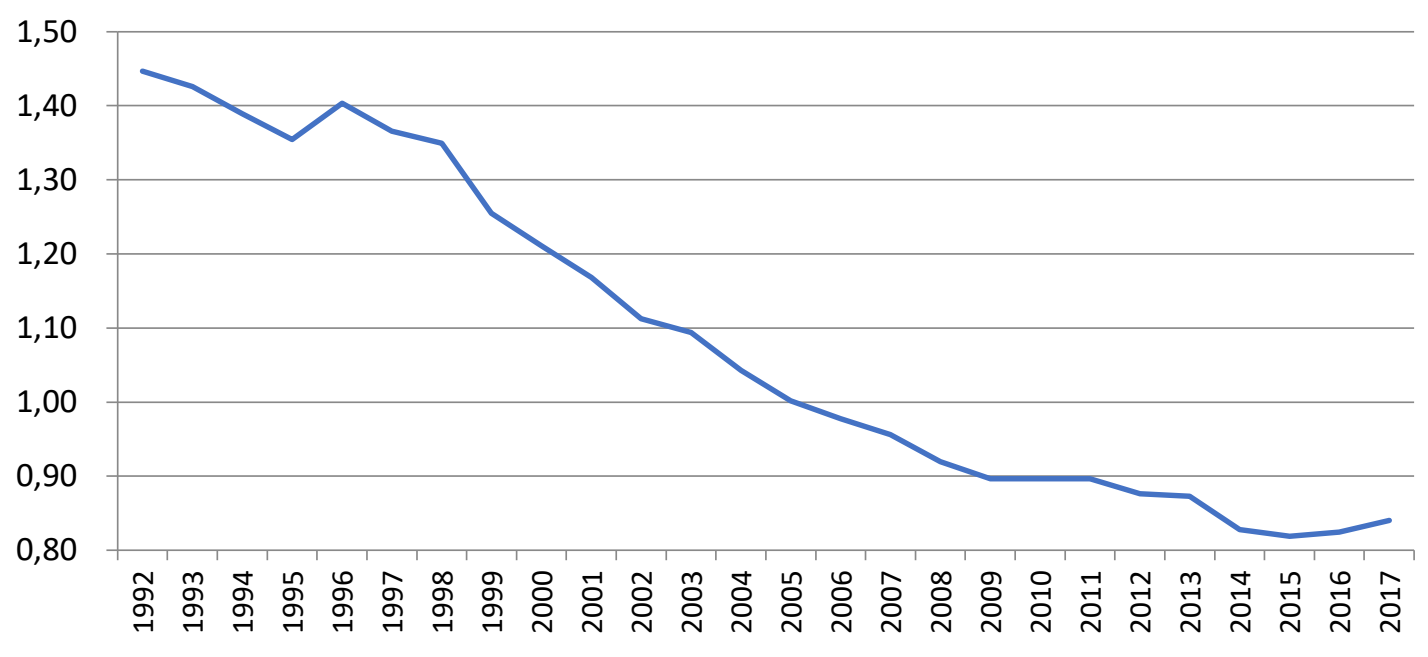

Fonte: elaboração própria com base nos dados do IPEADATA (PNAD/IBGE).

Esses resultados indicam que, ainda que a sociedade brasileira passe por um processo de transição demográfica acelerado, a capacidade da nossa estrutura econômica em garantir as condições de vida da população inativa ainda está evoluindo positivamente. Consequentemente, é possível supor que há espaço para 
a melhora das condições financeiras e atuariais do sistema previdenciário via aumento da parcela populacional contribuinte. Contudo, é importante que fique claro que esse resultado não reflete a situação previdenciária brasileira vivida durante esse período. Ele simplesmente aponta para um potencial produtivo que avançou de 1992 a 2016, a despeito de uma dinâmica econômica que pressionou as contas da previdência. Nesse sentido, uma questão importante é saber o quanto desse aumento da capacidade produtiva da economia brasileira vem sendo acompanhada de uma melhora na distribuição de renda? Caso a participação da renda do trabalho não evolua na mesma proporção dessa Razão, a melhora na sustentabilidade do sistema previdenciário fica limitada, especialmente se o financiamento do sistema ocorrer via salários. Para tornar mais claro esses argumentos, vamos utilizar um exemplo de uma economia hipotética.

Consideremos uma dada economia com taxa de crescimento populacional de $1,5 \%$ a.a., taxa de crescimento da produtividade de $2 \%$ a.a., e uma população inicial de 100. Em 35 anos, essa população terá alcançado o número de 168, um crescimento de $68 \%$. Consideremos que a população beneficiária seja 30 no início e sua taxa de crescimento seja de $2 \%$ (assume-se aqui uma taxa mais alta do que o crescimento populacional para expressar o processo de envelhecimento da população). Ao final dos 35 anos, a Razão de Dependência Previdenciária (RDP) terá apresentado uma piora (saindo de 0,30 para 0,35) que reflete a mudança demográfica no período. Contudo, se usarmos a Razão de Dependência proposta por Paley (1998), a evolução da população efetiva (que adiciona a produtividade) terá no mesmo período chegado ao número de 333, isto é, o dobro da população quando considerado apenas o crescimento demográfico. Como é de se esperar, nesse segundo cenário, a Razão de Dependência apresenta resultados melhores do que no primeiro caso (saindo de 0,3 para 0,17 ).

Após 35 anos, o trabalhador acrescido da produtividade acumulada (trabalhador efetivo) equivale ao dobro do trabalhador "convencional". Nesse sentido, retomando o argumento sobre a distribuição de renda, o fato de esse trabalhador ter ampliado sua capacidade produtiva não implica que houve um aumento de sua renda proporcional ao aumento da sua produtividade. Ele pode ter dobrado sua produtividade enquanto seu salário ampliou em $50 \%$. Assim, caso o imposto previdenciário incida sobre os salários, a melhora na Razão de Dependência Efetiva não gera como consequência um avanço na mesma proporção 
da capacidade de arrecadação do sistema previdenciário. Assim, como argumentado por Yasar (2013), quando se considera a incorporação da produtividade na análise da Previdência, a discussão do Financiamento do Sistema Previdenciário torna-se um elemento ainda mais fundamental no debate.

O principal mecanismo de financiamento da previdência é a contribuição dos seus participantes. Em um regime de repartição simples, o processo de envelhecimento populacional impõe um custo crescente para os beneficiários que terão de destinar uma parcela maior da sua renda para financiar o sistema, mesmo em um contexto de ampliação da produtividade. Assim, o processo de transição demográfica cria e fortalece um terceiro grupo que passa a disputar com capitalistas e trabalhadores uma parcela maior da renda gerada. Aqui entra o que Rada (2012) vai chamar de "terceira alma" do conflito distributivo. Quando não se considera a transição demográfica, a disputa pela renda se concentra entre capital e trabalho. A presença de aposentados e pensionistas impõe para um desses dois grupos um custo (manifesto através de um imposto previdenciário) que reduz a sua renda disponível.

\section{Custos macroeconômicos do sistema previdenciário}

Além do cálculo da Razão de Dependência Econômica Efetiva, que incorpora a produtividade e a informalidade, outra forma de analisar o sistema previdenciário é avaliar seus impactos macroeconômicos. Os principais trabalhos que analisam a previdência nessa perspectiva estão interessados em verificar de que modo a previdência se relaciona com o crescimento econômico. De um lado, alguns autores tentam identificar quais as condições de crescimento que seriam capazes de manter as contas da previdência sustentáveis no médio e longo prazo (Aisa; Pueyo, 2013). Outros trabalhos buscam entender qual o regime de aposentadoria oferece as melhores condições para o incremento do produto (Izerrougene, 2009). Nessa seção, a análise não focará em nenhum desses dois aspectos, mas em uma análise macroeconômica do sistema previdenciário analisado a partir do padrão de consumo dos aposentados e pensionistas.

Segundo Thompson (1998), esse custo é calculado como a participação do pagamento dos benefícios da previdência no total da produção nacional, isto é, a participação dos custos dos aposentados e seus dependentes no sistema econômico como um todo. Essa é uma medida útil porque demonstra diretamente a função 
distributiva do sistema de pensões em um modelo previdenciário de repartição simples (Yasar, 2013).

Como afirmado anteriormente, os custos atuariais e financeiros são medidas importantes a serem consideradas na avaliação de um sistema previdenciário, mas eles não são as únicas maneiras de fazê-lo. Como os sistemas de pensões são, geralmente, financiados pela combinação de contribuições sobre a renda do trabalho e sobre o capital, uma maior taxa paga pelos trabalhadores, compensada por uma menor taxa paga pelos empresários não altera o custo total da economia, o que muda é apenas a forma como ele é distribuído. Por isso, a necessidade de utilizar medidas mais gerais para calcular o custo macroeconômico de sustentar a população aposentada. Nesse sentido, Thompson (1998) propõe uma metodologia para calcular esse custo através da razão do consumo dessa população dividida pelo total da produção em uma economia.

Para chegar a esse indicador, ele inicia expressando o custo de sustentar a população beneficiária da previdência como o resultado do produto de três razões. A primeira delas é a taxa de consumo para todos os consumidores na economia em relação ao produto, isto é, a participação total do produto consumido ao invés de poupado. A segunda razão é o percentual da população total que é aposentada em relação à população beneficiária. E a terceira é a taxa de consumo dos aposentados e pensionistas comparada com a população como um todo. O custo econômico de sustentar os beneficiários da previdência pode ser apresentado algebricamente da seguinte forma:

$$
\operatorname{CSB}=\left(\frac{C}{Y}\right) \times\left(\frac{B}{P}\right) \times\left(\frac{M C B}{M C P}\right)
$$

Onde CSB é o Custo de Sustentar os Beneficiários, C é o total do consumo da economia, Y é o produto da economia, B é o total de Beneficiário na população, P é o total da população, MCB é a Média do Consumo por Beneficiário e MCP é a Média de Consumo do total da População. A Média do Consumo por Beneficiário também pode ser expressa por $C B / B$, em que $C B$ é o Consumo por Beneficiário e a Média do Consumo da População é $C / P$. A razão da Média de Consumo por Beneficiário (MCB) pela Média de Consumo da População (MCP) é o padrão de vida relativo dos beneficiários. Matematicamente ele pode ser expresso da seguinte forma: 


$$
\frac{M C B}{M C P}=\frac{C B}{B} / \frac{C}{P} \text { ou }\left(\frac{C B}{B}\right) \times\left(\frac{P}{C}\right)
$$

Assim, substituindo essa expressão na Equação 5, temos:

$$
C S B=\left(\frac{C}{Y}\right) \times\left(\frac{B}{P}\right) \times\left(\frac{C B}{B}\right) \times\left(\frac{P}{C}\right)
$$

Como as variáveis $\mathrm{C}, \mathrm{B}$ e $\mathrm{P}$ aparecem no denominador e numerador da equação, elas podem ser canceladas, o que nos revela a equação do Custo de Sustentar os Beneficiários (CSB), formulada por Thompson (1998):

$$
C S B=\left(\frac{C B}{Y}\right)=\frac{\text { Consumo dos Beneficiários }}{\text { Total da Produção Nacional }}=\frac{\text { Total de Benefícios }}{\text { Produto Interno Bruto }}
$$

Assim, a participação dos pagamentos de benefício na produção nacional pode ser medida em termos de produtos e serviços consumidos pela população aposentada e pensionista, ou, em outros termos, pelo total de Benefícios recebidos.

Com base nessa equação, é possível ver qual o custo de se sustentar os aposentados no Brasil. De acordo com os dados para a economia brasileira, no período da análise houve um aumento nesse indicador, que saiu de um pouco mais de $5 \%$ para quase $8 \%$, o que indica que houve um crescimento no custo de sustentar os aposentados e pensionistas no Brasil (Gráfico5 na linha azul). Isso coaduna com os resultados discutidos anteriormente, em que também se aponta para um aumento no total das transferências da União para o Regime Previdenciário. Contudo, como em diversas outras análises nesse trabalho, apesar desse aumento no custo, fica evidente que o período em que a economia brasileira manteve um ritmo de crescimento econômico maior (2004-2013), não por coincidência, o CSB mantevese relativamente estável, chegando a apresentar queda em alguns períodos (20072008 e 2010-2011). 


\section{Gráfico 5 - Custo macroeconômico dos beneficiários da Previdência}

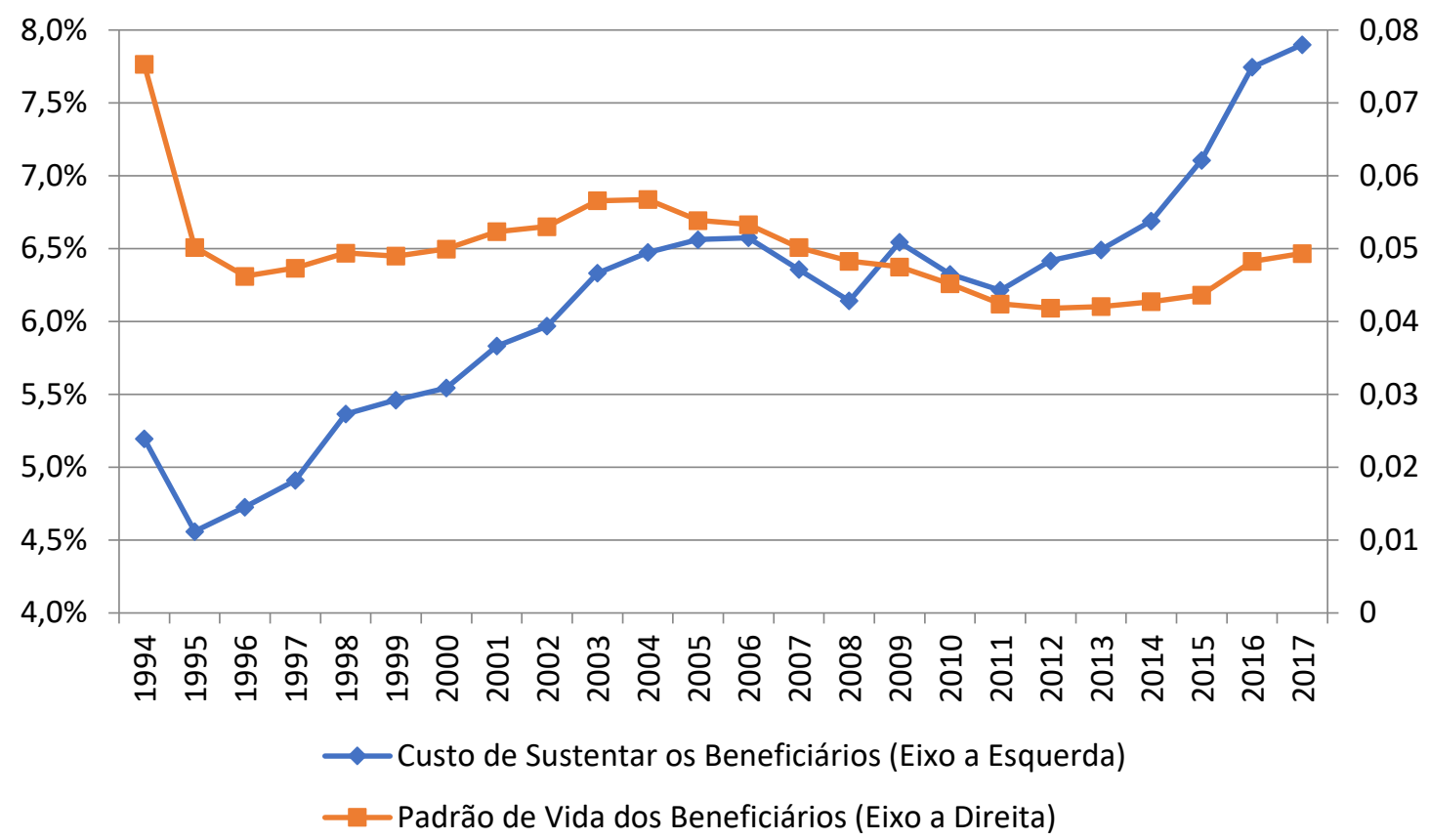

Fonte: elaboração própria com base nos dados da Previdência Social.

Além do custo de sustentar os beneficiários, para avaliar o custo macroeconômico do sistema previdenciário, também é possível calcular o Padrão de Vida dos Beneficiários (PVB) e observar o seu comportamento ao longo do tempo: $P V A=\left(\frac{\text { média do consumo dos beneficiários }}{\text { média do consumo da população }}\right)$. Como observado na linha vermelha do Gráfico 5, não houve grandes alterações no padrão de vida dos aposentados em comparação a média de consumo da população. Sendo assim, o aumento do custo em sustentar os aposentados não ocorreu por um aumento relativo do padrão de vida dos beneficiários em detrimento do conjunto da população.

\section{Considerações finais}

Uma análise do Regime Geral da Previdência que foque exclusivamente no equilíbrio atuarial e financeiro admite implicitamente que as aposentadorias e pensões não são um direito, mas uma recompensa pela contribuição realizada ao longo da vida. Essa abordagem do problema previdenciário justifica toda e qualquer reforma que tenha como foco a sustentabilidade do sistema, independente das suas consequências sociais. Contudo, quando se entende o sistema previdenciário como um direito, a análise sobre a sua sustentabilidade se altera 
substancialmente. Ao invés de esperar que cada indivíduo receba de acordo apenas com sua contribuição, assume-se que todo o cidadão tem o direito a uma renda no momento em que se torna incapaz de trabalhar, independente da sua contribuição, sendo o conjunto da sociedade responsável por garantir isso, através de outros mecanismos de financiamento.

Salários relativamente baixos e reduzido crescimento econômico podem prejudicar o sistema de pensões. Esta tendência é reforçada por uma alta taxa de emprego informal e o desemprego. Uma vez que essas características são levadas em consideração, a relação de dependência no sistema pode se tornar significativamente diferente de uma análise que se restringe à razão entre beneficiários e contribuintes da previdência. É o que o cálculo da Razão de Dependência Econômica Efetiva busca apresentar. Além disso, quando se observa o custo macroeconômico da previdência, outros fatores passam a ter mais significância na interpretação das dimensões do nosso problema previdenciário.

Esses diagnósticos levantados ao longo desse trabalho apontam que, apesar de haver um problema de financiamento do sistema previdenciário, ele não é tão grave quanto parece em um primeiro momento. Além disso, eles não eliminam a necessidade de reformas no Regime Geral, mas altera tanto o modo como entendemos o Regime Geral quanto os mecanismos a serem usados para reverter o atual quadro que se encontra a previdência. Nesse sentido, as transferências da União devem ser incluídas no cálculo da previdência porque elas foram criadas para complementar as Receitas Previdenciárias em um contexto de ampliação de direitos. Isso não significa, todavia, que não se deva buscar garantir um nível mais eficiente para essas transferências, de modo que elas não tenham uma trajetória insustentável do ponto de vista das contas públicas.

Reduzir as distorções do sistema - como os elevados benefícios recebidos por alguns grupos -, rever alguns parâmetros do sistema, buscar uma maior sustentabilidade dos gastos são estratégias que devem ser aplicadas. Contudo, é importante destacar que elas, sozinhas, não modificam estruturalmente a condição de sustentabilidade do sistema. É necessário buscar estratégias de desenvolvimento que melhorem as condições de trabalho, os níveis de renda e o acesso aos direitos trabalhistas no mercado de trabalho brasileiro, para assim construir um sistema previdenciário mais sustentável. 
A Constituição Federal de 1988, fruto das lutas democráticas e sociais que marcaram o fim da ditadura, ao instituir um Regime Previdenciário que atendesse a maioria dos brasileiros, deixa claro em sua concepção que a Previdência não é uma "restituição" ou "recompensa" pelo tempo trabalhado e sim um direito. Mesmo estabelecendo uma estrutura de contribuições mínimas, o sistema previdenciário brasileiro já inicia com um problema de equilíbrio financeiro estrutural como consequência da nossa estrutura econômica marcada pela desigualdade e exclusão. Ao refletir sobre a previdência, é fundamental ter clareza dessas condições.

\section{Referências}

ANSILIERO, G.; RANGEL, L.; PAIVA, L.; STIVALI, M.; BARBOSA, E. A desoneração da folha de pagamentos e sua relação com a formalidade do mercado de trabalho. Texto para Discussão do IPEA, n. 1341, 2008.

BACHA, E. Elementos para uma economia política das reformas do governo Lula. Revista de Economia Política, v. 24, n. 1, 2004.

BARROS, R.; FRANCO, S.; MENDONÇA, R. Discriminação e segmentação no mercado de trabalho e desigualdade de renda no Brasil. Texto para Discussão do IPEA, n. 1288, 2007.

BELTRÃO, K. A Dinâmica populacional brasileira e a previdência social. São Paulo em Perspectiva, v. 9, p. 1-6, 1995.

BORDONARO, N. La seguridad social y el mercado laboral en América. Revista Seguridad Social, n. 240, 2003.

CAETANO, M.; MONASTÉRIO, L. Previdência social e desigualdade regional no Brasil: uma abordagem multiescalar. Texto para Discussão do IPEA, n. 1992, 2014.

CAMARANO, A.; KANSO, S.; FERNANDES, D. Envelhecimento populacional, perda da capacidade laborativa e políticas públicas brasileiras entre 1992 e 2011. Texto para Discussão do IPEA, n. 1890, 2013.

FRANÇA, A. A Previdência social e a economia dos municípios. Brasília: ANFIP, 2011. 
GENTIL, D. A política fiscal e a falsa crise da seguridade social brasileira: análise financeira do período 1990-2005. 2006. 357 p. Tese (Doutorado em Economia) - Faculdade de Ciências Econômicas, Universidade Federal do Rio de Janeiro, Rio de Janeiro, 2006.

GENTIL, D.; ARAÚJO, E.; PUTY, C.; SILVA, C. Uma análise não convencional para o problema da previdência social no Brasil: aspectos teóricos e evidências empíricas. Revista da ABET, v. 16, n. 1, p. 138-159, 2017.

GIAMBIAGI, F.; MENDONÇA, J.; BELTRÃO, K.; ARDEO, V. Diagnóstico da previdência social no Brasil: o que foi feito e o que falta reformar? Texto para Discussão do IPEA, n. 1050, 2004.

GIAMBIAGI, F.; ALÉM, A. Finanças públicas: teoria e prática no Brasil. Rio de Janeiro: Elsevier, 2011.

INSTITUTO BRASILEIRO DE PLANEJAMENTO TRIBUTÁRIO - IBPT. Estudos do IBPT: estudo sobre sonegação fiscal das empresas brasileiras. Curitiba: IBGE, 2009.

MARQUES, R.; BATICH, M.; MENDES, A. Previdência social brasileira um balanço da reforma. São Paulo em Perspectiva, v. 17, n. 1, p. 111-121, 2003.

MARRI, I.; WAJNMAN, S.; ANDRADE, M. Reforma da previdência social: simulações e impactos sobre os diferenciais de gênero. Revista Brasileira de Estudos Populacionais, v. 28, n. 1, p. 37-56, 2011.

MATOS, P.; MELO, F.; SIMONASSI, A. Análise da solvência do regime geral da previdência social no Brasil. Revista de Estudos Econômicos, v. 43, n. 2, p. 301333, 2013.

MELLO, L.; MOCCERO, D. Brazil's fiscal stance during 1995-2005: the effect of indebtedness on fiscal policy over the business cycle. Paris: OECD Economics Department. 2006.

NERI, M. Informalidade. In: TAFNER, P.; GIAMBIAGI, F. (Orgs.). Previdência no Brasil: debates, dilemas e escolhas. Rio de Janeiro: IPEA, 2007, p. 285-319.

PAIVA, L.; ANSILIERO, G. A Desoneração da contribuição patronal sobre a folha de pagamentos uma solução à procura de problemas. Planejamento $e$ Políticas Públicas, v. 32, p. 9-36, 2009. 
PAIVA, L.; ANSILIERO, G.; BARBOSA, E. Financiamento da previdência social: impactos de uma eventual desoneração da folha salarial. In: SCHWARZER, H. (Org.). Coleção previdência social estudos e pesquisas da secretaria de políticas de previdência social. Brasília: Ministério da Previdência Social (MPS), 2009, p. 132-158.

PALEY, T. The economics of social security: an old Keynesian perspective. Journal of Post Keynesian Economics, v. 21, n. 1, p. 93-110, 1998.

PUTY, C.; FRANCÊS, C.; CARVALHO, S.; SILVA, M.; SILVA, C. Quão acuradas são as projeções financeiras e atuariais do regime geral da previdência social? Revista da ABET, v. 16, n. 1, p. 160-173, 2017.

RADA, C. Social security tax and endogenous technical change in an economy with aging population. Metroeconomica, v. 63, n. 4, p. 727-756, 2012.

REIS, C.; TURRA, C. Desigualdade regional na distribuição dos recursos previdenciários: uma análise das transferências intrageracionais e de período. Texto para Discussão do CEDEPLAR, n. 447, 2011.

REIS, P.; SILVEIRA, S.; BRAGA, M.; COSTA, T. Impactos das aposentadorias e pensões no nível de bem-estar social dos domicílios de Minas Gerais. Revista de Contabilidade Financeira, v. 26, n. 67, p. 106-118, 2015.

ROCHA, F. Política fiscal através do ciclo e operação dos estabilizadores fiscais. Revista Economia, v. 10, n. 3, p. 483-499, 2009.

SILVA, E.; SCHWARZER, H. Proteção social, aposentadorias, pensões e gênero no Brasil. Texto para Discussão do IPEA, n. 934, 2002.

THOMPSON, L. Older and wiser: the economics of public pension. Washington: The Urban Institute Press, 1998.

ULYSSEA, G. Segmentação no mercado de trabalho e desigualdade de rendimentos no Brasil: uma análise empírica. Texto para Discussão do IPEA, n. 1261, 2007.

VIEIRA FILHO, J.; SANTOS, G.; FORNAZIER, A. Distribuição produtiva e tecnológica da agricultura brasileira e sua heterogeneidade estrutural. In: INFANTE, R.; MUSSI, C.; ODDO, M. (Orgs.). Por um desenvolvimento inclusivo: o caso do Brasil. Santiago: Cepal, 2015, p. 171- 212.

YASAR, Y. The crisis in the Turkish pension system: A Post Keynesian perspective. Journal of Post Keynesian Economics, v. 36, n. 1, p. 131-152, 2013. 